\title{
Haldensleben: 8. Porzellanforum Sachsen-Anhalt
}

Am 24. Juni 2017 fand im Museum Haldensleben das mittlerweile 8. Porzellanforum statt. Zunächst führte Museumsleiterin Judith Vater durch die am 29. November 2016 bereits eröffnete Sonderausstellung „Es war einmal... Haldensleber Keramik 1945-1995“" (Bild 1). Haben die Anfänge keramischer Werke in Haldensleben ihren Ursprung bei Johann Gottlob Nathusius in Althaldensleben, so wurde die Keramikproduktion bis zum Ende des 2. Weltkrieges durch die Carstens-Uffrecht KG bestimmt. Mit dem VEB Keramische Werke Haldensleben existierte bis 1990 der größte Betrieb für Zierkeramik der DDR. Das in den 1970er Jahren erbaute moderne Werk für Sanitärkeramik hat als einziger Betriebsteil im Bestand der KERAMAG AG bis heute überlebt.

Folgende Vorträge wurden gehalten und z.T. mit wertvollen Sammlerobjekten bereichert:

- F. Kerbe, Hermsdorf: Die Farbenwelt in der technischen Keramik

- R. Hochmuth, Dessau: Chronologie des keramischen Gewerbes in Dessau von den Anfängen bis um 1990 unter Berücksichtigung der Porzellanmanufaktur von Nikolas Jean Baptiste Deruelle

- R. Uffrecht, Hermsdorf: Die Ausbildung von Keramikingenieuren in Hermsdorf

- J. Vater, Haldensleben: Rückschau auf sieben Porzellan-Foren. Diskussion über eine mögliche Erweiterung zum zukünftigen „KeramikForum Sachsen-Anhalt"

Nach einem Standortwechsel ins Kulturhistorische Museum in Magdeburg führte dort Detlef Dauer durch eine eigene, äußerst beeindruckende Sonderausstellung „Porzellan aus Magdeburg“ (Bilder 2, 3).

Das nächste Keramik-Forum Sachsen-Anhalt findet im Juni 2018 in Haldensleben statt.

F. Kerbe

Quellen:

(Bildnachweis: Museum Haldensleben)

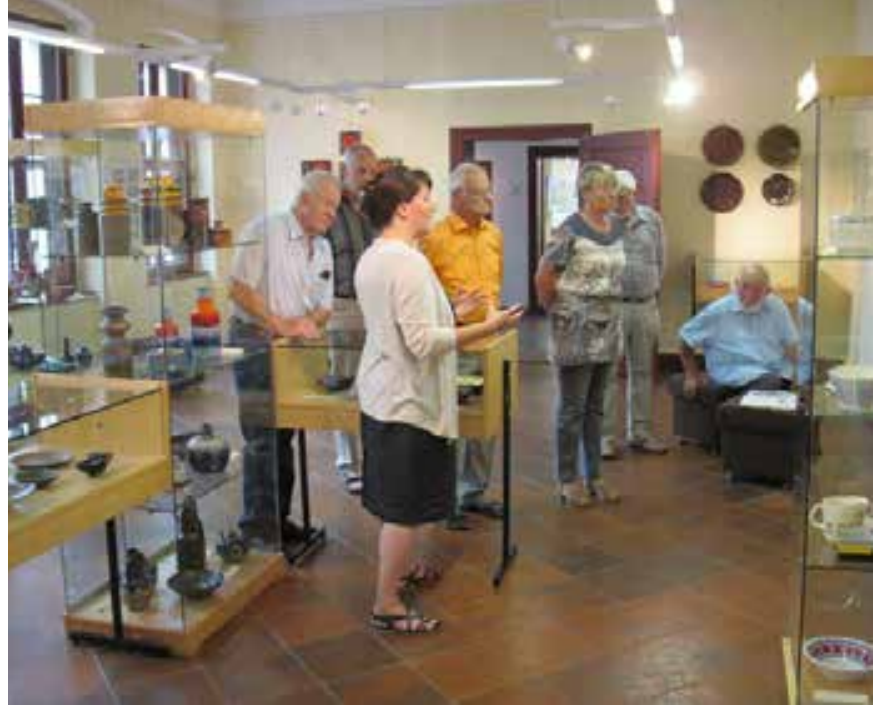

Bild $1 \bullet$ In der Sonderausstellung

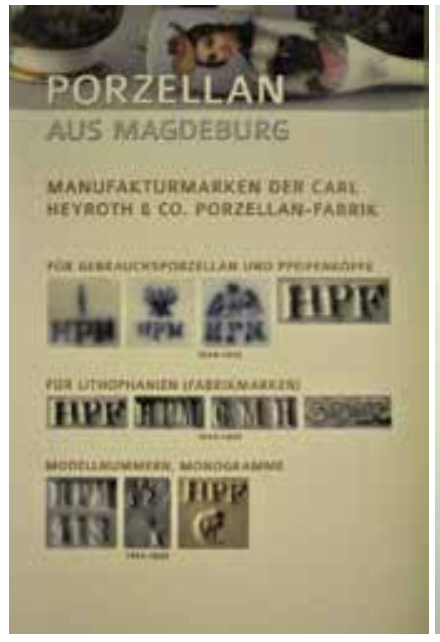

Bild 2 • Porzellan aus Magdeburg
MANUFAKTURMARKEN AUF BUCKAUER GEBRAUCHSPORZELLAN

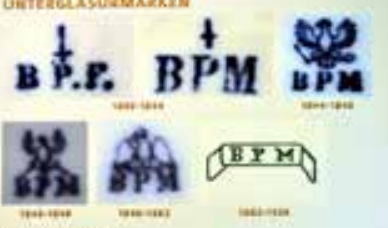

Pussmances

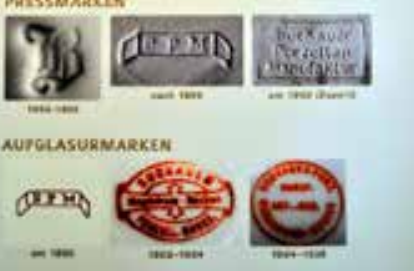

Bild 3 - Manufakturmarken auf Buckauer Gebrauchsporzellan

\section{Inserentenverzeichnis Keramische 06 | 2017}

Bayerische Unternehmensberatung Max Jürgen Schildgen

Goerg \& Schneider GmbH u. Co. KG

Expert Fachmedien GmbH

Helmut Kreutz Mahlwerke GmbH

Messe München GmbH

Rimini Fiera Spa

Sachverständigenbüro Gernandt-0sterkamp-Stengert

Stephan Schmidt KG
DE-Kaltenberg

141

DE-Siershahn

135

DE-Düsseldorf

138,167

DE-Haiger-Langenaubach

U1

DE-Düsseldorf

139

IT-Rimini

155

DE-Porta-Westfalica

159

DE-Dornburg/Langendernbach 